\title{
A ligand-free solid-supported system for Sonogashira couplings: applications in nucleoside chemistry $\dagger$
}

\author{
Neil K. Garg, ${ }^{a}$ Carolyn C. Woodroofe, ${ }^{a}$ Christopher J. Lacenere, ${ }^{b}$ Stephen R. Quake $+^{* c}$ and Brian M. Stoltz ${ }^{* a}$ \\ Received (in Bloomington, IN, USA) 25th April 2005, Accepted 16th May 2005 \\ First published as an Advance Article on the web 12th August 2005
}

DOI: 10.1039/b505737j

A mild heterogeneous, ligand-free protocol for Sonogashira and Heck couplings has been developed and used to access several biologically important deoxynucleoside derivatives in a facile manner.

Over the past several decades, transition metal-mediated crosscoupling reactions have emerged as powerful methods for the formation of carbon-carbon bonds. ${ }^{1}$ Of the many cross-coupling processes, the Pd-catalyzed Sonogashira coupling of aryl or vinyl halides with terminal alkynes ${ }^{2}$ has found high utility in modern organic chemistry, with applications ranging from natural product synthesis and pharmaceuticals to the development of organic materials $(\mathbf{1}+\mathbf{2} \rightarrow \mathbf{3}$, Fig. 1). Given the importance of the Sonogashira reaction, the discovery of improved catalyst systems continues to be an active area of research. In this communication, we describe a new set of solid-supported cross-coupling conditions that are extremely useful, particularly for the handling and isolation of highly polar compounds.

Our interest in the Sonogashira coupling was sparked by the crucial role it plays in nucleoside chemistry. ${ }^{3}$ More specifically, this transformation has been essential for the development of both traditional and modern DNA sequencing technologies. ${ }^{3,4}$ En route to novel reagents for sequencing on the single molecule level, ${ }^{5}$ we encountered difficulties separating the polar nucleoside product (6) from triethylammonium salts formed from the Sonogashira coupling of iodide $\mathbf{4}$ with protected propargylamine $\mathbf{5}$ (Scheme 1). ${ }^{6}$ Although this problem has been documented, ${ }^{6 a}$ only one solution has been reported, which involves the preparation and use of an expensive resin to neutralize the triethylammonium by-product as

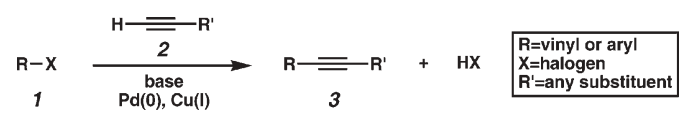

Fig. 1 The Sonogashira reaction.

${ }^{a}$ Division of Chemistry and Chemical Engineering, California Institute of Technology, 1200 East California Boulevard, MC 164-30, Pasadena, CA 91125, USA. E-mail: stoltz@caltech.edu; Fax: +1 626564 9297; Tel: +16263956064

${ }^{b}$ Division of Biology, California Institute of Technology, 1200 East California Boulevard, Pasadena, CA 91125, USA

${ }^{c}$ Division of Engineering and Applied Science, California Institute of Technology, 1200 East California Boulevard, Pasadena, CA 91125, USA

$\dagger$ Electronic supplementary information (ESI) available: experimental details and ${ }^{1} \mathrm{H}$ NMR spectra for all compounds. See http://dx.doi.org/ 10.1039/b505737j

t Current address: Department of Bioengineering, Stanford University, James H. Clark Center S170, Stanford, CA 94305, USA. E-mail: quake@stanford.edu; Fax: +1 626793 8675; Tel: +1 6507248891

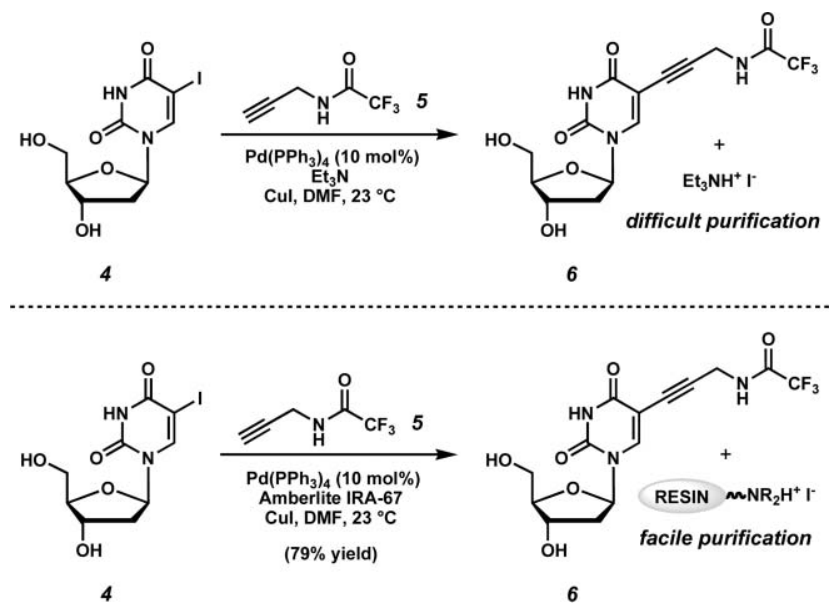

Scheme 1

part of the purification process. ${ }^{6,7}$ We reasoned that an alternative solution would be to substitute an affordable trialkylamine-bound resin for triethylamine in the Sonogashira reaction. By carrying out the identical cross-coupling reaction in the presence of Amberlite IRA- $67^{8}$ it was possible to isolate the desired Sonogashira product (6) in 79\% yield after filtration of the reaction media and purification by silica gel chromatography.

On the basis of a comprehensive study conducted by Kotschy and co-workers, ${ }^{9}$ we postulated that it might be possible to utilize a heterogeneous transition metal catalyst in our Sonogashira coupling to further simplify the purification process. In fact, upon simply substituting $\mathrm{Pd} / \mathrm{C}$ for $\mathrm{Pd}\left(\mathrm{PPh}_{3}\right)_{4}$, lowering the catalyst loading to $5 \mathrm{~mol} \% \mathrm{Pd}$, and conducting the reaction at $50{ }^{\circ} \mathrm{C}$, formation of 6 proceeded smoothly (Scheme 2). ${ }^{10,11}$ Moreover, cross-coupling took place in the absence of ligand additives typically employed in Sonogashira couplings, while in the presence of several heteroatom substituents.

We next explored the $\mathrm{Pd} / \mathrm{C}$ and Amberlite IRA-67-mediated Sonogashira coupling of a number of deoxynucleoside derivatives (Table 1). In addition to deoxyuridine 6 (dU, entry 1 ), both uridine
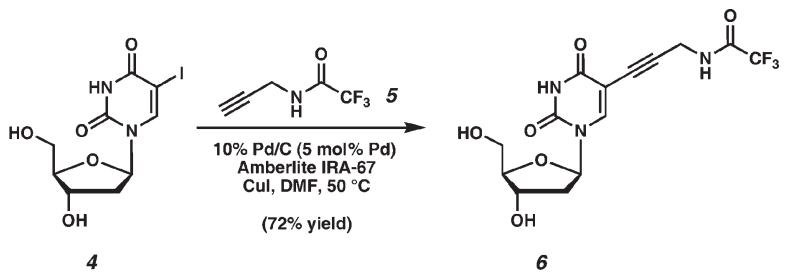

Scheme 2 
Table 1 Solid-supported Sonogashira coupling of deoxynucleoside derivatives $^{a}$

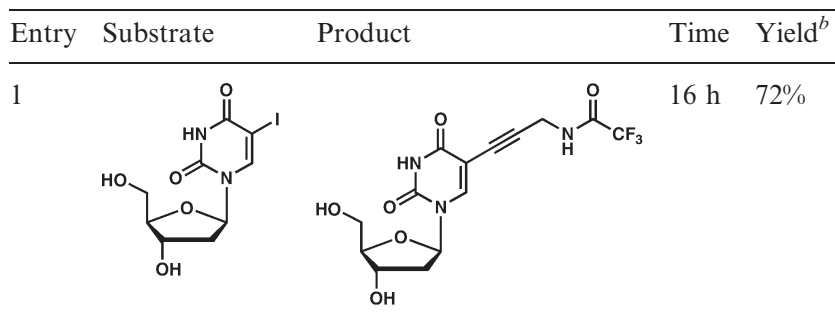

2<smiles>O=c1[nH]c(=O)n(C2OC(O)C(CO)O2)cc1I</smiles><smiles></smiles>

$10 \mathrm{~h} \quad 71 \%$
3

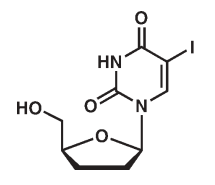<smiles>O=C(NCC#Cc1cn(C2CCCO2)c(=O)[nH]c1=O)C(F)(F)F</smiles>

$16 \mathrm{~h} \quad 69 \%$<smiles>NC1=NC(=O)N2C=C(I)C(=N1)C2CC(O)CO</smiles>

$5^{d}$<smiles>Nc1nc(Br)n2c(N)ncnc12</smiles>

$6^{d}$<smiles>Nc1nc2c(nc(Br)n2CC2CC(O)C(O)C2)c(=O)[nH]1</smiles>

$7^{e}$

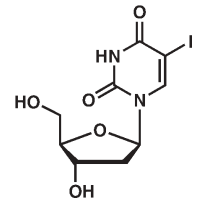

$25 \mathrm{~h} \quad 94 \%$

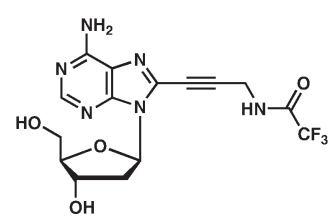

$7 \mathrm{~h} \quad 98 \%$

$11 \mathrm{~h} \quad 78 \%$
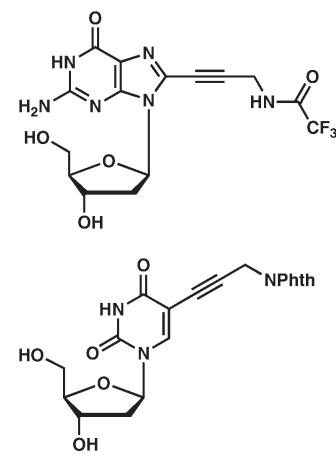

$14 \mathrm{~h} \quad 78 \%$

$8^{c, e, f}$
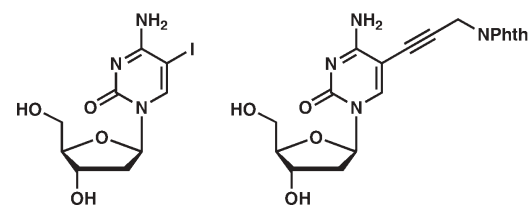

18 h $\quad 73 \%$

${ }^{a}$ Standard conditions: $10 \% \mathrm{Pd} / \mathrm{C}(5 \mathrm{~mol} \% \mathrm{Pd}), 5$ (2 equiv.), CuI (20 mol\%), Amberlite IRA-67 (5 equiv.), DMF (0.1 M), $50{ }^{\circ} \mathrm{C}$. ${ }^{b}$ Isolated yield. ${ }^{c} 10 \%$ Pd/C $\left(\begin{array}{llll}10 & \mathrm{~mol} \% & \mathrm{Pd}\end{array}\right) .{ }^{d} 10 \% \mathrm{Pd}\left(\mathrm{PPh}_{3}\right)_{4}$. ${ }^{e}$ Phthalyl protected propargyl amine used (2 equiv.). ${ }^{f} 60{ }^{\circ} \mathrm{C}$.

(U) and dideoxyuridine derivatives (ddU) were readily accessible under our heterogeneous conditions (entries 2 and 3). The latter of these products (i.e., entry 3 ) is particularly important since it is a

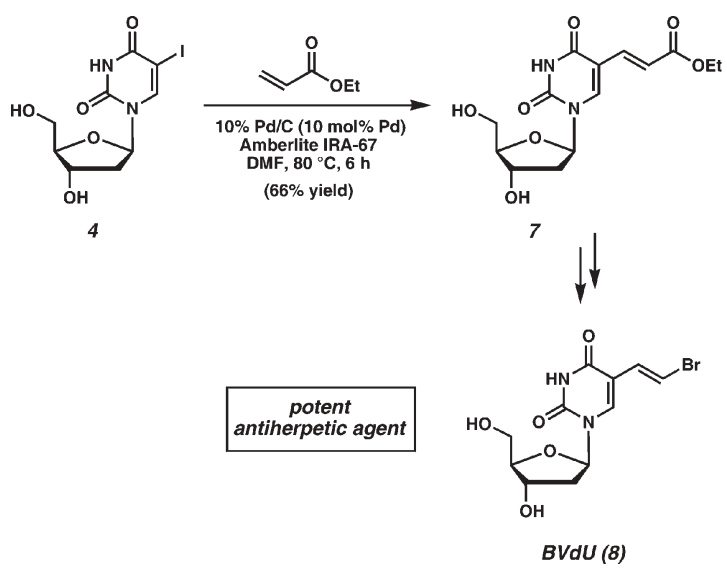

Scheme 3

key intermediate in the synthesis of conventional Sanger DNA sequencing reagents. ${ }^{4}$ While it was also possible to access $2^{\prime}$-deoxycytidine $(\mathrm{dC})$ derivatives under Pd/C-catalysis (entry 4), Sonogashira coupling of 8-bromo-2'-deoxyadenosine (dA) and 8-bromo-2'-deoxyguanosine $(\mathrm{dG})$ derivatives was rather sluggish. However, by employing a $\mathrm{Pd}\left(\mathrm{PPh}_{3}\right)_{4} /$ Amberlite IRA-67 system, good to excellent yields of cross-coupled products could be obtained for these substrates (entries 5 and 6). Finally, the use of phthalamide-protected propargyl amine in place of trifluoroacetamide 5 under our $\mathrm{Pd} / \mathrm{C}$ conditions also led to the formation of Sonogashira products (entries 7 and 8). These phthalamido reagents (entries 7 and 8), as well as their trifluoroacetyl analogs (entries 1 and 4) have been used to access fluorescently-labelled deoxynucleoside triphosphate derivatives for novel DNA sequencing technologies that are currently in development. ${ }^{12}$

Having developed a simple solid-supported system for Sonogashira couplings, we wondered if our conditions would be applicable to other cross-coupling reactions. In a preliminary finding, our heterogeneous reaction protocol was effective in promoting the Heck reaction ${ }^{13}$ of iodide 4 with ethyl acrylate to afford ethyl ester 7 in $66 \%$ yield (Scheme 3). Importantly, ester 7 has previously been converted to $\operatorname{BVdU}(\mathbf{8}),{ }^{14}$ a potent antiherpetic agent. ${ }^{3,15}$

In conclusion, we have developed a heterogeneous protocol for the Sonogashira reaction that employs $\mathrm{Pd} / \mathrm{C}$ as a catalyst and a resin-bound tertiary amine as a base. These conditions are particularly useful for the facile isolation of polar nucleoside compounds, which are otherwise difficult to access in pure form. In addition, Heck chemistry can be carried out using the same solid-supported reagents. Ultimately, we have used these crosscouplings to prepare several biologically important molecules. Applications of these methods to synthesize novel reagents for DNA sequencing are currently being investigated.

The authors thank the NIH (R01 HG003594), the Rosen Fellowship (for C. J. L.) and the NDSEG (pre-doctoral fellowship to N. K. G.) for financial support. We also thank E. James Petersson for helpful discussions.

\section{Notes and references}

1 (a) Metal-Catalyzed Cross-Coupling Reactions, ed. F. Diederich and P. J. Stang, Wiley-VCH, Weinheim, 1998; (b) H. Geissler, in Transition Metals for Organic Synthesis, ed. M. Beller and C. Bolm, Wiley-VCH, 
Weinheim, 1998, vol. 1, ch. 2.10, p. 158; (c) J. Tsuji, Transition Metal Reagents and Catalysts, Wiley, Chichester, U.K., 2000, ch. 3, p. 27.

2 (a) K. Sonogashira, Y. Tohda and N. Hagihara, Tetrahedron Lett., 1975, 16, 4467; (b) K. Sonogashira, Comprehensive Organic Synthesis, ed. B. M. Trost and I. Fleming, Pergamon Press, Oxford, 1991, vol. 3, ch. 2.4, p. 521, and references therein; (c) N. A. Bumagin, L. I. Sukhomlinova, E. V. Luzikova, T. P. Tolstaya and I. P. Beletskaya, Tetrahedron Lett., 1996, 37, 897; (d) T. Hundertmark, A. F. Littke, S. L. Buchwald and G. C. Fu, Org. Lett., 2000, 2, 1729; (e) M. Erdélyi and A. Gogoll, J. Org. Chem., 2001, 66, 4165.

3 For a pertinent review, see: L. A. Agrofoglio, I. Gillaizeau and Y. Saito, Chem. Rev., 2003, 103, 1875.

4 J. M. Prober, G. L. Trainor, R. J. Dam, F. W. Hobbs, C. W. Robertson, R. J. Zagursky, A. J. Cocuzza, M. A. Jensen and K. Baumeister, Science, 1987, 238, 336.

5 I. Braslavsky, B. Hebert, E. Kartalov and S. R. Quake, Proc. Natl. Acad. Sci. U. S. A., 2003, 100, 3960.

6 (a) F. W. Hobbs, J. Org. Chem., 1989, 54, 3420; (b) T. R. Battersby, D. N. Ang, P. Burgstaller, S. C. Jurczyk, M. T. Bowser, D. D. Buchanan, R. T. Kennedy and S. A. Benner, J. Am. Chem. Soc., 1999, 121, 9781.

7 For purification, the chloride form of AG1-X8 resin must be converted to its bicarbonate form. AG1-X8 (chloride form) is commercially available from Biorad at a cost of $\$ 331 \mathrm{USD} / 500$ grams.

8 Amberlite IRA-67 is commercially available from Aldrich Chemical Company, Inc. at a cost of $\$ 36 \mathrm{USD} / 500$ grams.

9 Z. Novák, A. Szabó, J. Répási and A. Kotschy, J. Org. Chem., 2003, 68, 3327.

10 For related cross-coupling reactions catalyzed by $\mathrm{Pd} / \mathrm{C}$, see: $(a)$ C. P. Mehnert, D. W. Weaver and J. Y. Ying, J. Am. Chem. Soc., 1998, 120, 12289; (b) S. I. Khan and M. W. Grinstaff, J. Org. Chem., 1999, 64, 1077; (c) M. A. De la Rosa, E. Velarde and A. Guzman, Synth. Commun., 1990, 20, 2059; (d) H. Hagiwara, Y. Shimizu, T. Hoshi, T. Suzuki, M. Ando, K. Ohkubo and C. Yokoyama, Tetrahedron Lett., 2001, 42, 4349; (e) L. Djakovitch and K. Koehler, J. Am. Chem. Soc.,
2001, 123, 5990; (f) H. Sakurai, T. Tsukuda and T. Hirao, J. Org. Chem., 2002, 67, 2721; (g) C. R. LeBlond, A. T. Andrews, Y. Sun and J. R. Sowa, Org. Lett., 2001, 3, 1555; (h) D. S. Ennis, J. McManus, W. Wood-Kaczmar, J. Richardson, G. E. Smith and A. Carstairs, Org. Process Res. Dev., 1999, 3, 248; (i) K. Köhler, R. G. Heidenreich, J. G. E. Krauter and J. Pietsch, Chem. Eur. J., 2002, 8, 622; (j) G. Zhang, Synlett, 2005, 619.

11

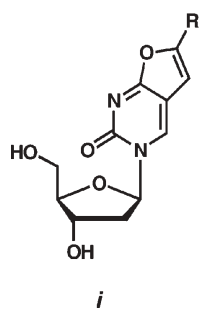

In some cases, furanopyridine by-products (e.g., i) are formed, albeit in minor quantities. Compounds of this type are potent antiviral agents. See: (a) T. S. Mansour, C. A. Evans, M. Charron and B. E. Korba, Bioorg. Med. Chem. Lett., 1997, 7, 303; (b) A. Carangio, C. McGuigan, G. Andrei, R. Snoeck, E. De Clercq and J. Balzarini, Antiviral Chem. Chemother., 2001, 12, 187, see also references therein.

12 G. Giller, T. Tasara, B. Angerer, K. Mühlegger, M. Amacker and H. Winter, Nucleic Acids Res., 2003, 31, 2630.

13 For reviews of the Heck reaction, see: $(a)$ A. B. Dounay and L. E. Overman, Chem. Rev., 2003, 103, 2945; (b) I. P. Beletskaya and A. V. Cheprakov, Chem. Rev., 2000, 100, 3009; (c) C. Amatore and A. Jutand, J. Organomet. Chem., 1999, 576, 254.

14 M. Ashwell, A. S. Jones, A. Kumar, J. R. Sayers, R. T. Walker, T. Sakuma and E. De Clercq, Tetrahedron, 1987, 43, 4601.

15 H. Griengl, W. Hayden, W. Schwarz, H. Bachmayer and B. Rosenwirth, Eur. J. Med. Chem., 1985, 20, 105. 